\title{
Study on the Cultivation and Development Strategies of High- tech Enterprises in Shandong Province under the Background of the Transformation of Old Growth Drivers to New Ones
}

\author{
Hang Wang ${ }^{1}$ \\ ${ }^{1}$ School of Economics and Trade, Shandong Management University, Ji Nan, China
}

\begin{abstract}
At present, the new round of scientific \& technological revolution and industrial transformation is accelerating. The integration and penetration of information technology, biotechnology, new materials and new energy technologies are driving mass technological breakthroughs in almost all fields, bringing more opportunities for innovation and space for development. Under the background of accelerating scientific and technological revolution and industrial reform, the situation of scientific and technological work at home and abroad is still complex and grave. As an important means to guide enterprises' scientific \& technological innovation in China, high-tech enterprises are an important force to accelerate the transformation from old growth drivers to new ones and promote high-quality economic development. This paper analyzes the status quo and the problems in the cultivation of high-tech enterprises in Shandong Province, such as relatively small overall number of high-tech enterprises, insufficient reserve forces, lack of financing channels and low intensity of research \& development investment. The difficulties existing in the process of promoting the cultivation of high-tech enterprises in the Shandong Province are deeply explored in the form of enterprise research and expert interview, the shortage of high-quality intellectual property reserves and financing difficulties faced by enterprises in each growth stage are analyzed, and practical policy suggestions are put forward.
\end{abstract}

\section{Introduction}

At present, China's economy is shifting from the stage of rapid growth to the stage of high-quality development. We must attach great importance to optimizing the economic structure, transforming the mode of development and transforming the growth drivers, and promote reform in quality, efficiency and drivers. At the fifth Plenary Session of the 19th CPC Central Committee in 2020, it was proposed that we should uphold innovation as the core of China's modernization drive, take self-reliance in science and technology as the strategic support for China's development, improve the national innovation system, and speed up the building of a country strong in science and technology. We should strengthen the country's strategic scientific and technological forces, enhance enterprises' technological innovation capabilities, stimulate the innovation vitality of talents, and improve the system and mechanism for scientific and technological innovation. At the Provincial Science and Technology Innovation Conference in July 2020, Liu Jiayi, Secretary of the Provincial Party Committee, pointed out that "the only way to accelerate the transformation from old growth drivers to new ones and realize high-quality development is to promote scientific and technological innovation with greater efforts and accelerate the construction of a high-tech province." As an important means to guide enterprises' scientific and technological innovation in China, high-tech enterprises are an important index to measure the level of regional scientific \& technological and economic development and an important force to promote regional economic development. At present, the cities with a good momentum of scientific \& technological innovation have all realized the importance and necessity of cultivating and developing high-tech enterprises, and have made great efforts to cultivate and develop high-tech enterprises.

\section{Research Status}

High and new technology enterprises have become important market subjects of scientific and technological innovation in China. Scholars at home and abroad pay close attention to and study the development of high and new technology enterprises, which provides rich theoretical basis and practical methods for the cultivation and growth of high enterprises. Cheng Xiang[1] took the financial policies on science and technology issued by 31 provinces of China as the research object, selected 558 new and high technology enterprises, and empirically tested the relationship between financial policies on 
science and technology and the competitiveness of new and high technology enterprises. His research showed that policies on fiscal science and technology investment and policies on science and technology capital market could significantly enhance the competitiveness of new and high technology enterprises. Based on the empirical test of the panel data of high-tech enterprises from 2008 to 2017, Wang Yikai[2] concluded that the preferential tax rate and the policy of additional deduction on R\&D expenses have an incentive effect on the R\&D input and output of enterprises, and the incentive effect of the policy of additional deduction on R\&D expenses is greater than the preferential tax rate policy in terms of the R\&D input of enterprises. Huo Jianglin[3] made a factor analysis of the growth performance of high-tech enterprises and compared the difference between high and low growth performance, and concluded that the support of relevant government policies could significantly improve the growth performance of high-tech enterprises.

On the basis of the understanding of the general rules of the development of high-tech enterprises, researchers have studied the cultivation and development of high-tech enterprises from the aspects of enterprises themselves and financial institutions. Chen Jianli[4] believes that the development of regional science and technology finance can positively stimulate enterprises' R\&D investment and effectively alleviate the R\&D financing constraints of non-state-owned enterprises. Guo Xiuqiang[5] believes that R\&D investment has a significant positive impact on the market performance of high-tech enterprises. Hightech enterprises need to invest a large amount of capital in the R\&D stage, but due to the uncertainty of technology and market, the characteristics of high investment, high risk and high uncertainty increase the financing plight of science and technology enterprises[6]. Therefore, with the continuous consolidation and enhancement of the dominant position of enterprises' innovation investment, how to raise funds through multiple channels to increase R\&D investment so as to improve the use efficiency of funds and promote the transformation of scientific and technological achievements has become an urgent problem for most high-tech enterprises at present. With the launch of the Science and Technology Innovation Board (Star Market) of Shanghai Stock Exchange and the establishment of the registration system for stock issuance, high-tech enterprises continue to increase $R \& D$ investment by financing in the stock market, which would become more rapid and convenient[7]. However, the domestic bond market has no obvious financing function for enterprises. We can effectively solve the financing difficulties of small and medium-sized technology-based enterprises by reducing the credit rating requirements of issuers, reducing the cost of issuing bonds, and establishing multi-level bond markets with the multi-level approval requirements for bond issuance and the limit of bond issuance[8]. Chen Zhaohui[9] found that, through the construction of the evaluation index system for the patent financing ability of high-tech enterprises, the technology patent pledge financing of high-tech enterprises can be an effective method to solve the capital shortage of enterprises.

\section{The Status Quo of Cultivation of High-tech Enterprises in Shandong Province}

\subsection{The Number of New and High Technology Enterprises Has Increased Significantly}

With the introduction of various policies for the cultivation and support of high-tech enterprises by departments at all levels in the Shandong Province, the number of high-tech enterprises in the Shandong Province has achieved rapid growth in recent years. According to the statistics, in 2018, the total number of high-tech enterprises in the Shandong Province during the period of validity was 8,919 , an increase of $41.6 \%$ compared with that in 2017. In 2019, the total number of high-tech enterprises in the Shandong Province during the period of validity exceeded 10,000 for the first time and reached 11,465 , with a year-on-year growth of 28.5 percent (see Table I.). In 2019, the output value of high-tech industries in the Shandong Province increased by $2.2 \%$ year-on-year, and the industrial output value accounted for $40.14 \%$ of the industrial output value of regions above designated size, $3.22 \%$ higher than that of 2018 .

TABLE I. THE Number OF High-TECH ENTERPRISES IN EACH City of Shandong Province from 2016 to 2019

\begin{tabular}{|c|c|c|c|c|c|}
\hline $\begin{array}{c}\text { Serial } \\
\text { number }\end{array}$ & City & 2016 & 2017 & 2018 & 2019 \\
\hline 1 & Qingdao & 1348 & 2053 & 3112 & 3829 \\
\hline 2 & Jinan & 751 & 1074 & 1636 & 2241 \\
\hline 3 & Weifang & 468 & 542 & 705 & 808 \\
\hline 4 & Yantai & 370 & 453 & 635 & 822 \\
\hline 5 & Jining & 287 & 317 & 399 & 503 \\
\hline 6 & Weihai & 228 & 297 & 396 & 502 \\
\hline 7 & Zibo & 236 & 282 & 383 & 512 \\
\hline 8 & Linyi & 208 & 271 & 369 & 541 \\
\hline 9 & Dezhou & 134 & 157 & 196 & 244 \\
\hline 10 & Dongying & 111 & 149 & 206 & 263 \\
\hline 11 & Tai'an & 119 & 139 & 197 & 271 \\
\hline 12 & Zaozhuang & 99 & 111 & 138 & 170 \\
\hline 13 & Binzhou & 84 & 100 & 124 & 167 \\
\hline 14 & Liaocheng & 74 & 97 & 158 & 202 \\
\hline 15 & Heze & 62 & 92 & 121 & 171 \\
\hline 16 & Rizhao & 53 & 92 & 144 & 219 \\
\hline 17 & Laiwu & 60 & 74 & I & I \\
\hline \multicolumn{2}{|c|}{$\begin{array}{l}\text { The Total of Shandong } \\
\text { Province }\end{array}$} & 4692 & 6300 & 8919 & 11465 \\
\hline
\end{tabular}




\subsection{A Development and Cultivation Mechanism with Different Gradients Have Begun to Take Shape}

By sorting out and analyzing the high-tech industries in Shandong Province, the provincial science and technology competent departments follow the growth rules of science and technology enterprises, actively build the whole-lifecycle echelon cultivation system which provides incubation, growth support and promotion for science and technology enterprises, and accelerate the expansion of small and medium-sized science and technology enterprises and new and high technology enterprises in Shandong Province. The incubation carrier with significant incubation performance will be given a reward of up to 2 million yuan. We shall improve the policies on innovation vouchers and risk compensation for loans for the transformation of scientific and technological achievements, and provide a comprehensive subsidy of up to 1 million yuan to the winners of the innovation competition of small and medium-sized technology-based enterprises.

\subsection{The Preferential Policy of Additional Deduction for R\&D Expenses Has Been Effective}

The preferential policy of additional deduction of R\&D expenses is an important measure to encourage scientific and technological innovation and promote supply-side structural reform, which is of great significance to strengthening the impetus for technological innovation of enterprises and promoting the quality and efficiency of the economy. Since 2015, the government has adjusted the policy of additional deduction on R\&D expenses, which has further expanded the coverage and preferential intensity of the policy and effectively promoted the R\&D and innovation activities of enterprises. Influenced by the incentive effect of preferential policies of additional deduction on R\&D expenses, enterprises in Shandong Province continuously increase their R\&D investment, pay more attention to the development of independent intellectual property rights, and continuously improve their overall R\&D ability.

\section{Problems Existing in the Cultivation of high-tech enterprises in Shandong Province}

However, there is still a certain gap between Shandong Province and other advanced provinces in the cultivation and development of high-tech enterprises. Take Qingdao as an example. In 2019, there were 3,829 high-tech enterprises in Qingdao, ranking the first in Shandong Province. However, it still lags far behind Shenzhen (16,900 high-tech enterprises), Guangzhou (12,000 hightech enterprises) and other cities (see Table II.). Especially with Sino-US trade friction, a new generation of information technology industry represented by $5 \mathrm{G}$ in China has been comprehensively suppressed by relevant countries led by the United States with security issues. In addition, by directly raising tariff barriers, technology monopoly and other measures, the United States has squeezed the profit margins of export-oriented high-tech enterprises. Many high-tech enterprises in Shandong Province are listed in the entity list, which directly affects the development of related fields in the industry. With the outbreak of COVID-19, consumer demand at home and abroad has declined, enterprises' short-term production has stagnated, operating costs have risen, and corporate revenues have plummeted. These problems, together with the difficult and expensive financing, have a serious impact on the small and medium-sized high-tech enterprises as the reserve force of high-tech enterprises, and have a negative impact on the subsequent source cultivation of high-tech enterprises and the sustainable development of high-tech enterprises. According to the summary of materials related to the cultivation and identification of high-tech enterprises in Shandong Province in September 2020, currently, the cultivation of high-tech enterprises reported by the provincial science and technology authorities is mainly faced with the following problems:

TABLE II. RANKING OF HIGH-TECH ENTERPRISES IN 15 SUBPROVINCIAL CITIES FROM 2017 TO 2019

\begin{tabular}{|l|l|l|l|l|}
\hline $\begin{array}{c}\text { Serial } \\
\text { number }\end{array}$ & \multicolumn{1}{|c|}{ City } & \multicolumn{1}{|c|}{$\mathbf{2 0 1 7}$} & \multicolumn{1}{|c|}{$\mathbf{2 0 1 8}$} & \multicolumn{1}{|c|}{$\mathbf{2 0 1 9}$} \\
\hline 1 & Guangzhou & 8700 & 11794 & 12000 \\
\hline 2 & Hangzhou & 2844 & 3780 & 5526 \\
\hline 3 & Nanjing & 1844 & 3126 & 4590 \\
\hline 4 & Wuhan & 2827 & 3536 & 4417 \\
\hline 5 & Chengdu & 2473 & 3110 & 4149 \\
\hline 6 & Qingdao & 2053 & 3112 & 3826 \\
\hline 7 & Xi'an & 1839 & 2623 & 3711 \\
\hline 8 & Jinan & 1074 & 1636 & 2238 \\
\hline 9 & Xiamen & 1425 & 1626 & 1950 \\
\hline 10 & Shenyang & 847 & 1230 & 1836 \\
\hline 11 & Dalian & 800 & 1200 & 1750 \\
\hline 12 & Changchun & 433 & 653 & 1322 \\
\hline 13 & Harbin & 614 & 774 & 1050 \\
\hline 14 & Shenzhen & 11230 & 14418 & 16900 \\
\hline 15 & Ningbo & 1479 & 1739 & 2135 \\
\hline
\end{tabular}

\subsection{The Overall Number of Enterprises with High Quality Intellectual Property Rights in Shandong Province is Relatively Small}

According to the Measures for the Administration of the Accreditation of High-Tech Enterprises (No. 32 [2016] of the Ministry of Science \& Technology), core independent intellectual property rights of enterprises are an important part of the cultivation process of high-tech enterprises. Intellectual property rights account for $30 \%$ of the evaluation score and have a core position in the recognition of high-tech enterprises. The lack of 
intellectual property reserves will have a great impact on the follow-up work of applying for high-tech enterprises. According to the overall situation of Shandong Province, the intellectual property reserve of enterprises is not optimistic. In addition, according to the work experience of various cities in recent years, there is the situation that the declaring enterprises attach more importance to quantity than quality of intellectual property rights. From the perspective of the composition of patents, the proportion of utility models and design patents is relatively large, but the invention patents, which have high technical content and represent regional and urban innovation capacity, account for a relatively small proportion.

\subsection{Financing Difficulty of New and High Technology Enterprises}

4.2.1 Bank loans. As the technology and products researched and developed by high-tech enterprises are of certain advancement and complexity, the success of research and development is affected by many uncertain factors. Chinese commercial banks which occupy the dominant position in the financial system, on the one hand, due to the lack of market mechanism, commercial banks' early support for the high-tech industry has formed a certain scale of non-performing assets, on the other hand, the operation principle of the bank is to take prudence as the first principle, which means that they would not invest on a large scale in high and new technologies that are in the high-risk initial stage. In addition, one of the characteristics of the high-tech industry is that most hightech enterprises belong to small and medium-sized enterprises. For banks, credit risks are relatively high, and the mortgage guarantee they can provide is very limited. Therefore, it is difficult for banks to effectively meet their capital needs in consideration of risks. Even in foreign countries, bank loans are not the main way of financing for high-tech enterprises, especially for small and medium-sized high-tech enterprises.

\subsubsection{In terms of the development of venture} capital. The reason why American high-tech enterprises have such a good development trend can be attributed to the strong promotion of venture capital and the supported emerging small and medium-sized enterprises mainly in high-tech industries. For example, Anderson of MIT said that without venture capital, there would be no new economy. However, even in Jiangsu Province, the province with relatively fast development in China, the venture capital is still in the initial stage, which need to be further improved. Venture capital funds are often invested in private enterprises with development potential. However, most venture capitals are invested in the growth stage of enterprises, because in this period, we can clearly see whether the investment object has development potential. When the business is in the seed stage or the start-up stage, the enterprise products are still in the market development stage, and the products have not been fully recognized by the market, so these enterprises don't have much cash inflows. Venture capital cannot judge its development potential and foreground accurately. That's why high-tech enterprises would encounter a lot of financing difficulties in the beginning. In addition, venture capital institutions generally have a short investment cycle (2-3 years), and they rarely make investment which costs more than 5 years. However the high-tech industry is a industry with a long payback period. The cycle consists of the start of research and development, success in research and development, commercialization of results and large-scale commercial production generally takes many years. The short-term investment of venture capital institutions will affect the development and production of enterprise products.

4.2.3 Financing in Capital market. The capital market cannot meet the financing needs of small and medium-sized technology-based enterprises. With the gradual development of the capital market, direct financing through the securities market is used by small and medium-sized technology-based enterprises as an important way to raise huge funds in a short time. At present, China's stock market mainly includes the Main Boards of Shanghai and Shenzhen Stock Exchange, Shenzhen SME Board, GEM Board, National Equities Exchange and Quotations (NEEQ) and other systems. On the whole, the financing system of the securities market that can meet the multi-level financing needs has been basically established. However, in order to control financial risks, each market has set a high market entry standard, and the market function originally envisaged has not played its due role. Although small and medium-sized technology-based enterprises can use the capital markets of developed countries for overseas financing, many of them may face various litigation risks even if they go public in the face of the strict foreign regulatory systems. As an important part of the capital market, the development of the bond market is extremely unbalanced compared with that of the securities market. The bond market is small in size, low in marketization, and fragmented in issuance and trading. In particular, the development of corporate bonds is even slower. All of these make it difficult for small and medium-sized technological enterprises to get financial support from the capital market. In 2019, the Shanghai Stock Exchange launched the Star Market. Its biggest characteristic is the implementation of the registration system for stock issuance. Its core task is to serve the scientific and technological innovation enterprises that conform to the national strategy, break through the key core technologies and gain high market recognition. This will be of great help to China's scientific and technological innovationoriented enterprises in opening up financing channels and docking the financing development of the capital market.

\subsection{Emerging industries are developing slowly}

The cultivation of high-tech enterprises is an important support for the optimization and upgrading of urban industries. All the advanced cities (such as Shenzhen) have promoted the overall strength of the cities through 
the rapid development of emerging industries represented by the new generation of information technology, thus promoting the rapid growth of small and medium-sized enterprises into high-tech enterprises. As a big province of traditional industries, the industrial structures of most areas of Shandong Province are mainly dominated by traditional manufacturing industries. Except for some advantageous enterprises, general processing manufacturing enterprises have low scientific and technological content and weak independent research and development ability. In some regions, the number of new enterprises is not large, their growth rates are not fast, and the source of high-quality emerging enterprises is insufficient. In particular, the number of enterprises represented by the new generation of information technology is relatively small, and the number of hightech enterprises in line with the declaration fields of strategic emerging industries is relatively small.

\section{Strategies and Suggestions for Accelerating the Cultivation and Development of High-tech Enterprises in Shandong Province}

1) In the cultivation of new and high technology enterprises, independent intellectual property rights should be taken as the starting point to cultivate innovation ability. Intellectual property management and services not only provide support for the cultivation of new and high technology enterprises, but also are the key to promote the sustainable and stable development of innovation ability. In the process of cultivating new and high technology enterprises, enterprises should pay more attention to intellectual property rights, encourage and support enterprises to actively apply for intellectual property rights, and promote further development of the title of enterprises through core independent intellectual property rights. We shall actively guide enterprises to make layout in advance and timely follow up relevant patent applications according to the progress of $R \& D$ projects and the requirements for the application of hightech enterprise. Because the authorization period of class I intellectual property rights is relative long, we shall actively guide enterprises to make targeted and planned layout before applying for the title of high-tech enterprise.

2) We shall increase support for the cultivation and construction of grassroots high-tech enterprises. We shall promote the informationization in the cultivation of hightech enterprises by grades and classifications, promote the service level for the cultivation of high-tech enterprises. On the basis of building the provincial cultivation database for high-tech enterprises, the information resources of cultivation of high-tech enterprises should be moderately extended to grassroots departments. We shall help support the development of large high-tech enterprises and the informatization platform for industrial development. Industry and commerce, taxation, environmental protection, security and market supervision departments shall share information, so that real-time data such as the number of scientific researchers, the amount of intellectual property rights, the approval of scientific and technological projects, and the main financial indicators, etc. in enterprises which are applying for high-tech enterprises could be mastered. We shall also further straighten out the inter-department audit process, realize the "whole-process online" for the cultivation and application of high-tech enterprises, so as to reduce the workload of applying enterprises.

3) We shall broaden the financing channels, further deepen the financial reform, and actively explore the way of private capital into the high-tech industry. In the investment and financing channels, we shall establish a set of venture capital mechanism suitable for high-risk characteristics, and gradually form a diversified, multilevel and multi-channel system of investment and financing for science and technology through government allocations, financial loans, self-financing by enterprises and social collection of funds. We shall further promote the multi-level and diversified development of the science and technology capital market, so as to provide more diversified external financing channels and effective financing mechanism for innovative, entrepreneurial and growing enterprises. We shall give appropriate policy support and tax incentives to venture capital projects and give full play to the long-term role of venture capital in enterprise $R \& D$ activities. We shall establish a sound mechanism for integrating science and technology with finance, improve the development of the science and technology financial system, and guide the flow of financial resources to the science and technology innovation system. As an institutional arrangement to guide the allocation of financial resources to the field of science and technology innovation, the science and technology financial system plays a positive role in stimulating the R\&D investment of high-tech enterprises and promoting the sustainable growth of enterprises.

4) Accelerating the cultivation of new and high technology enterprises in emerging industries. At present, China has occupied a place in the field of the new generation of information technology in the world, and its industrial scale takes the lead in the world. There is huge space for China to use information technology to transform the traditional economy and cultivate new growth drivers for the digital economy. Shandong Province should grasp the opportunity, and make the new generation of information technology industry bigger and stronger. It shall focus on fostering a new generation of high-tech information technology enterprises represented by artificial intelligence, quantum information, mobile communications, the Internet of Things, and blockchain, promote the fundamental transformation of the manufacturing industry pattern and enterprise form, drive transformation with innovation, drive stock with increment, and promote industries within the province to the middle and upper end of the value chain. 


\section{Conclusions}

At present, the cultivation of high and new technology enterprises in Shandong Province is mainly faced with the following problems: The overall number of high and new technology enterprises is relatively small, the reserve forces are insufficient, the development of emerging industries is slow, the financing channels are insufficient, and the R\&D investment is inadequate. By combing the working system of cultivation of provincial high and new technology enterprises, this article adopts the research forms such as corporate research to explore the difficulties existing in the process of promoting the cultivation of high and new technology enterprises in the whole province. In view of the practical effect of science and technology policy on the development of high-tech enterprises, this paper makes a selective analysis on the shortage of highquality intellectual property reserves of enterprises and the financing difficulties faced by science and technology enterprises in each growth stage, and practical policy suggestions are put forward.

\section{References}

1. Cheng Xiang, Zhang Rui, Zhang Feng. Has the policy of science and technology finance improved the competitiveness of enterprises?-- Evidence from high-tech listed companies [J]. Research on Economics and Management, 2020, 41(08), pp. 131144.

2. Wang Yikai, Zhou Yongmei, Wang Xiaolin. Tax Rate Preference, Additional Deduction Policy and Enterprise Innovation -- An Empirical Study based on Propensity Score matching [J]. Journal of Finance and Economics, 2020(08), pp. 58-66.

3. Huo Jianglin. Growth performance evaluation of high-tech listed companies on GEM [J]. Statistics \& Decision, 2020, 36(17), pp, 185-188.

4. Chen Jianli. Development of science and Technology finance, Financing constraints and Enterprise R\&D Investment -- Empirical evidence from A-share listed companies [J]. Science and Technology Management Research, 2020 ,40(14), pp. 131-139.

5. Guo Xiuqiang, Sun Yanming. Research and development investment, technology accumulation and market performance of high-tech enterprises [J]. Studies in Science of Science, 2020, 38(09), pp. 1630-1637.

6. Yao Mengqi, $\mathrm{Xu}$ Min. Influence of financing efficiency on R\&D investment in high-tech enterprises [J]. Science and Technology Management Research, 2019, 39(01), pp. 129-136.

7. $\mathrm{Xu}$ Shibo. Star Market helps enterprise innovation and development, while incubator become the "cradle" for cultivating enterprises in star market[J]. Science and Technology Industry of China, 2020(09), pp. $40-41$.

8. Zhang Wujun, Li Mingxiu, Ding Qiang. Financing difficulties of small and medium-sized technologybased enterprises and countermeasures [J]. Sub National Fiscal Research, 2020(04), pp. 87-92.

9. Chen Zhaohui, Zhou Zhijuan. Research on evaluation index system of patent financing ability of high-tech enterprises [J]. Science and Technology Management Research, 2019, 39(10), pp. 133-138. 